\title{
Evidence for the Induction of Key Components of the NOTCH Signaling Pathway via Deltamethrin and Azamethiphos Treatment in the Sea Louse Caligus rogercresseyi
}

\author{
Sebastian Boltaña, Jaqueline Chávez-Mardones, Valentina Valenzuela-Muñoz and \\ Cristian Gallardo-Escárate * \\ Laboratory of Biotechnology and Aquatic Genomics, Interdisciplinary Center for Aquaculture \\ Research (INCAR), Department of Oceanography, University of Concepción, Concepción 4030000, Chile; \\ sboltana@udec.cl (S.B.); jchavez@udec.cl (J.C.-M.); valevalenzuela@gmail.com (V.V.-M.) \\ * Correspondence: crisgallardo@udec.cl; Tel.: +56-41-220-3422
}

Academic Editor: Jun Li

Received: 30 December 2015; Accepted: 18 February 2016; Published: 12 May 2016

\begin{abstract}
The extensive use of organophosphates and pyrethroids in the aquaculture industry has negatively impacted parasite sensitivity to the delousing effects of these antiparasitics, especially among sea lice species. The NOTCH signaling pathway is a positive regulator of $\mathrm{ABC}$ transporter subfamily $\mathrm{C}$ expression and plays a key role in the generation and modulation of pesticide resistance. However, little is known about the molecular mechanisms behind pesticide resistance, partly due to the lack of genomic and molecular information on the processes involved in the resistance mechanism of sea lice. Next-generation sequencing technologies provide an opportunity for rapid and cost-effective generation of genome-scale data. The present study, through RNA-seq analysis, determined that the sea louse Caligus rogercresseyi (C. rogercresseyi) specifically responds to the delousing drugs azamethiphos and deltamethrin at the transcriptomic level by differentially activating mRNA of the NOTCH signaling pathway and of $\mathrm{ABC}$ genes. These results suggest that frequent antiparasitic application may increase the activity of inhibitory mRNA components, thereby promoting inhibitory NOTCH output and conditions for increased resistance to delousing drugs. Moreover, data analysis underscored that key functions of $\mathrm{NOTCH} / \mathrm{ABC}$ components were regulated during distinct phases of the drug response, thus indicating resistance modifications in C. rogercresseyi resulting from the frequent use of organophosphates and pyrethroids.
\end{abstract}

Keywords: Caligus rogercresseyi; deltamethrin; azamethiphos; RNA-seq; NOTCH signaling pathway; $\mathrm{ABC}$ transporters

\section{Introduction}

Caligus rogercresseyi, like Lepeophtheirus salmonis, is a marine ectoparasite that infests farmed and wild salmonids, causing high economic losses for the industry [1,2]. The current control method for caligidosis, or infection with $C$. rogercresseyi, is the use of chemical treatments. Insecticides commonly used in salmonid farming include avermectins (e.g., emamectin benzoate), pyrethroids (e.g., deltamethrin (DM)), organophosphates (e.g., azamethiphos (AZA)), and hydrogen peroxide [3]. Apart from the environmental damage inherent to any large-scale therapeutic drug administration, pesticide resistance is a growing concern. For example, different delousing drug also induce treatment resistance in sea lice [3-6].

The NOTCH signaling pathway is a positive regulator of ATP-binding cassettes $(\mathrm{ABC})$ transporter subfamily $C(A B C C)$ expression. In arthropods, ATP-driven efflux transport systems have been 
linked with resistance to pesticides and other drugs [7-10]. However, there are few studies on the $\mathrm{NOTCH}$ and $\mathrm{ABC}$ interactome in marine ectoparasites treated with delousing drugs, and insight on this subject could provide important information regarding the generation and modulation of pesticide resistance. NOTCH is a heterodimeric Type 1 transmembrane receptor coded by one of four NOTCH genes (Noctch1-NOTCH4) [11]. Interaction with these receptors activates $\gamma$-secretase and the A Disintegrin and Metalloprotease complexes, resulting in the cleavage of the intracellular C-terminal fragment of NOTCH $\left(N^{I C}\right)$. Following cleavage, $\mathrm{N}^{\mathrm{IC}}$ is translocated to the interior of the nucleus, where it changes the CBF1/RBP-Jk/Suppressor of Hairless/LAG-1 (CSL) transcription factor from a transcriptional repressor to a transcriptional activator through the substitution of a repressor complex with an activator complex [12]. The CSL/N ${ }^{I C}$ activation complex trans-activates various target genes, including genes from HES/HEY family members that actively repress a tissue-specific $\mathrm{NOTCH}$-signaling pathway. Modifications in the expressional regulation of the NOTCH protein, ligands, and targets have been described in a number of tumor tissues in humans [13]. Intracellular forms of NOTCH have also been implicated in the resistance of thymocytes to glucocorticoids [14]. Moreover, $\mathrm{N}^{\mathrm{IC}}$ participation has been reported in resistance to adriamycin, cisplatin, etoposide, and taxol in MCF7 cells, MOLT4 cells, breast adenocarcinoma cell lines, and infantile lymphoma T-cells, respectively [15].

The ABC transporters are membrane proteins that mediate the unidirectional transport of biological substrates linked to ATP hydrolysis. These transporters are recognized members of the multidrug resistance protein family [16]. The superfamily of $A B C$ transporters in invertebrates is divided into eight subfamilies $(A B C A-A B C H)$, which are differentiated by domain and sequence architectures $[17,18]$. Of note, the $B, C$, and $G$ subfamilies have direct roles in processes of detoxification [19]. In humans, the $A B C C 1$ proteins transport a wide range of xenobiotics, physiological substrates, and other components [20]. The overexpression of $A B C C 1$ in tumor tissues has been clearly associated with clinical drug resistance in cases of intestinal and esophageal cancers [13]. In terms of pesticide resistance, there is a close relationship in L. salmonis between the expression levels of P-glycoprotein, a member of the $A B C B$ subfamily, and emamectin benzoate resistance [21]. Moreover, expressional regulation of the $A B C C 1$ gene is associated with the promoter of the $5^{\prime} \mathrm{UTR}$ through various transcription factors, including the GC box, activator protein 1, and E-box elements [22]. Furthermore, the promoter region of $A B C C 1$ interacts with the transcription factor core-binding factor 1 , an interaction activated by $N^{I C}$ in association with the NOTCH signaling pathway [23].

The extensive use of organophosphates and pyrethroids in the aquaculture industry has negatively impacted parasite sensitivity to the delousing effects of antiparasitics, especially in sea lice such as L. salmonis $[6,24]$. However, little is known about the molecular mechanisms underlying drug transport that are affected by these chemicals. This situation is partly due to a lack of genomic and molecular information, especially in C. rogercresseyi. Next-generation sequencing technologies have revolutionized the fields of genomics and transcriptomics, providing an opportunity for rapidly and cost-effectively generating genome-scale data [25]. Considering the negative impacts of caligidosis and the increasing instance of resistance, it is highly relevant to study the transcriptomic performance of $C$. rogercressey treated with DM and AZA to establish the effects of drug concentrations on mRNA abundances in key molecular processes, such as in the NOTCH signaling pathway and ABC transporters. RNA-seq analysis determined that the sea louse $C$. rogercresseyi specifically responded to both delousing drugs at a transcriptomic level by differentially activating mRNA of the NOTCH signaling pathway and of ABC genes. Groucho and HDAC are key regulators of NOTCH signaling pathway mediating the transcriptional repression of NOTCH downstream, the present study shows for the first time its mRNA regulation and interaction with $\mathrm{NOTCH}$ gene cassettes after drug treatment. Additionally, the expression of single nucleotide polymorphisms (SNPs) was predicted for NOTCH and $\mathrm{ABC}$ components to facilitate gene mapping and genetic variation analysis in $C$. rogercresseyi exposed to DM and AZA. 


\section{Results}

\subsection{Identification and Expression of NOTCH Signaling Pathway Gene Components from C. rogercresseyi}

From the de novo assembly of transcripts obtained from sequencing six developmental stages of C. rogercresseyi $[25,26] 15$ transcripts participating in the distinct stages of NOTCH pathway signaling were identified, while 27 transcripts were annotated for ABC transporters (Table 1). This information allowed establishing a putative NOTCH signaling pathway in $\mathrm{C}$. rogercresseyi. The identified transcripts had $E$-values between $1 \times 10^{-29}$ and 0 , with high homology to sequences submitted in the NCBI gene bank for arthropods, such as Daphnia pulex (ID: 6669), Drosophila melanogaster (ID: 7227), and L. salmonis (ID: 72036). In silico analysis of NOTCH signaling pathway expression showed significant expressional changes in pathway components in individuals exposed to the delousing drugs. Histone deacetylase $(H D A C)$ was upregulated in the group challenged by DM, while NOTCH1, 2 were slightly upregulated in this same group (Figure 1A). The upregulated components of the NOTCH signaling pathway modulated by AZA included NOTCH1, 2 (Figure 1B). There was high presenilin-1 (PSEN1) expression in the control group, but this significantly decreased in the group exposed to AZA. PSEN also was upregulated in the control and decreased after the DM treatment, suggesting that the both drugs AZA and DM promote the decrease in its mRNA abundance. RNA-seq analysis showed that components of the NOTCH signaling pathway modulated by AZA presented differences in expression compared to the control group. The GROUCHO ii, HDAC4, HDAC6, NOTCH (1-2), and NUMB genes were differentially expressed in the AZA group compared to the control. The percentage of sea lice that died during treatment is indicated in Table 2. The survival rate of C. rogercresseyi was lower for 3 ppb of DM than for 3 ppb of AZA. Large differences in survival were also found between sea louse sexes after DM treatment, with 3 ppb inducing the death of all male sea lice.

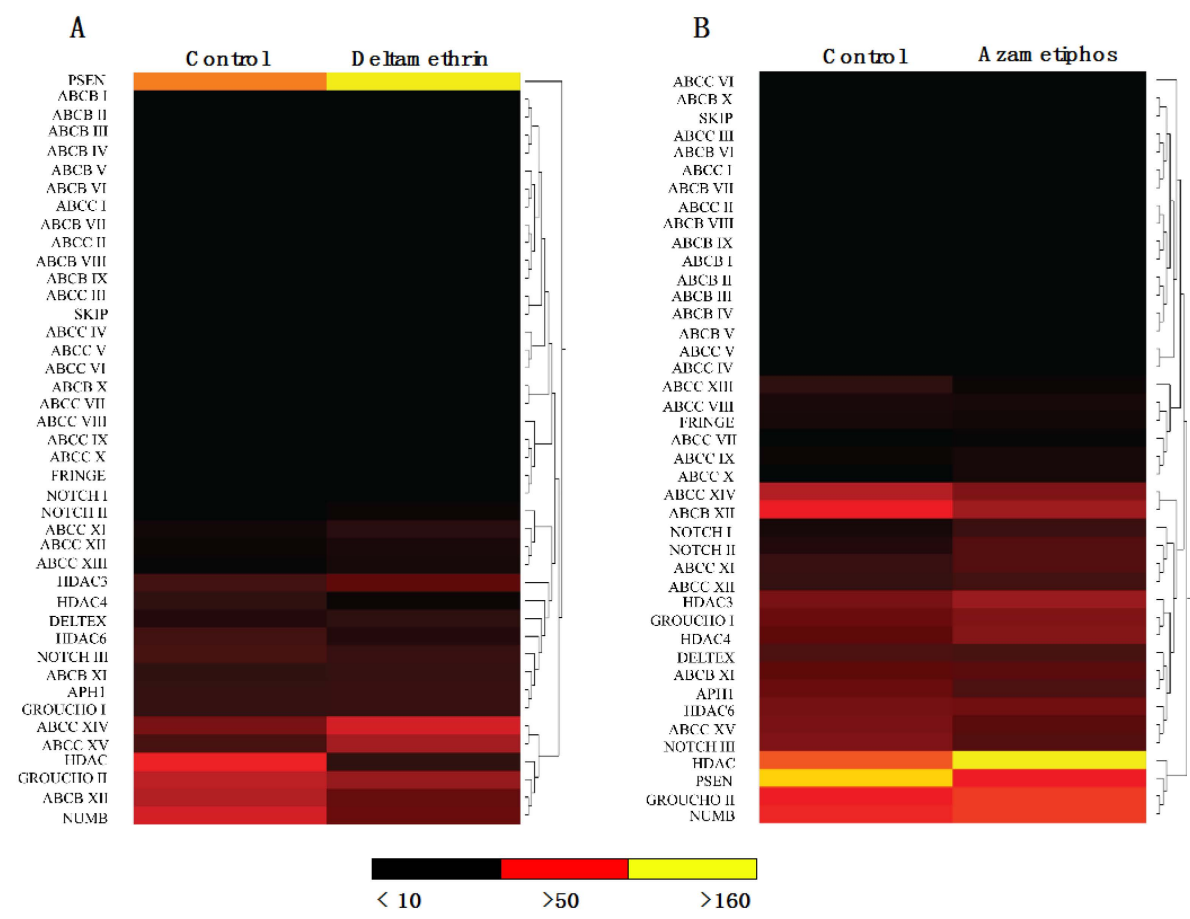

Figure 1. Heat map analysis of NOTCH signaling pathway components. Heat map generated by RNA-seq analysis for components of the NOTCH signaling pathway in adult $\mathrm{C}$. rogercresseyi treated with antiparasitics. (A) Deltamethrin and (B) Azamethiphos. Hierarchical clustering was performed using the Euclidean distance matrix and complete linkage method, while the Manhattan metric distance was used for hierarchical cluster analysis. Analyses were conducted in Cluster3/TreeView open software. 
Table 1. NOTCH pathway genes identified for C. rogercresseyi and differential transcription expressions between adults exposed to a delousing drug (azamethiphos (AZA) or deltamethrin (DM)) and the control group.

\begin{tabular}{|c|c|c|c|c|c|c|c|}
\hline \multirow{2}{*}{ Name } & \multirow{2}{*}{ Lowest $E$-Value } & \multirow{2}{*}{ Accession ( $E$-Value) } & \multirow{2}{*}{ Description } & \multicolumn{2}{|c|}{ Adults DM/Adults Control } & \multicolumn{2}{|c|}{ Adults AZA/Adults Contro } \\
\hline & & & & Fold Change & $p$-Value & Fold Change & $p$-Value \\
\hline$A B C C V$ & $2 \times 10^{-33}$ & ETN58310.1 & $\begin{array}{c}\text { Multidrug resistance protein } 2 \\
\text { (ATP-binding cassette protein c) [Anopheles darlingi] }\end{array}$ & 0.83 & 0 & 0 & 0 \\
\hline$A B C C V I$ & $6 \times 10^{-98}$ & EHJ72514.1 & $\begin{array}{c}\mathrm{ABC} \text { transporter family C protein } \mathrm{ABCC} 2 \\
\text { [Danaus plexippus] }\end{array}$ & 1.92 & 0 & 0.165 & 0 \\
\hline ABCC VIII & 0 & XP_004081991.1 & $\begin{array}{l}\text { PREDICTED: multidrug resistance-associated protein } \\
\text { 4-like [Oryzias latipes] }\end{array}$ & -0.97 & 0 & -1.6 & 0 \\
\hline$A B C C X I$ & 0 & XP_008276233.1 & $\begin{array}{l}\text { PREDICTED: multidrug resistance-associated } \\
\text { protein } 4 \text { [Stegastes partitus] }\end{array}$ & 0.50 & 0 & 0.49 & 0 \\
\hline$A B C C I V$ & $3 \times 10^{-59}$ & EFX68457.1 & $\begin{array}{l}\text { ATP-binding cassette, sub-family C, } \\
\text { member } 4 \text { [Daphnia pulex] }\end{array}$ & -0.58 & 0 & $\mathrm{NN}$ & 0 \\
\hline$A B C C I X$ & 0 & KFQ99756.1 & $\begin{array}{c}\text { Multidrug resistance-associated protein } 1 \\
\text { [Nipponia nippon] }\end{array}$ & 1.18 & 0 & 0.7 & 0 \\
\hline$A B C C X I V$ & $3 \times 10^{-77}$ & XP_001862061.1 & Multidrug resistance-associated protein 14 & 0.60 & 0 & -0.4 & 0 \\
\hline$A B C B$ XII & 0 & AHC54388.1 & $\begin{array}{l}\text { [Culex quinquerasclatus] } \\
\text { P-glycoprotein [Caligus rogercresseyi] }\end{array}$ & -0.58 & 0 & -0.61 & 0 \\
\hline ABCC III & $1 \times 10^{-58}$ & XP_001022386.1 & $\begin{array}{l}\text { ABC transporter family protein } \\
\text { [Tetrahymena thermophila] }\end{array}$ & $\mathrm{NN}$ & 0 & 0 & 1 \\
\hline$A B C B V I$ & $1 \times 10^{-39}$ & WP_018508877.1 & $\begin{array}{l}\text { [etranymena thermopnia] } \\
\text { ABC transporter [Thiobacillus thioparus] }\end{array}$ & 0 & 1 & 0 & 1 \\
\hline$A B C C I$ & $1 \times 10^{-40}$ & EAS00380.2 & $\begin{array}{l}\text { ABC transporter C family protein [Tetrahymena } \\
\text { thermophila SB210] }\end{array}$ & 0 & 1 & 0 & 1 \\
\hline$A B C B$ VII & $1 \times 10^{-45}$ & WP_016832902.1 & $\begin{array}{c}\text { Amino acid ABC transporter ATP-binding protein } \\
\text { [Herbaspirillum lusitanum] }\end{array}$ & 0 & 1 & 0 & 1 \\
\hline$A B C C I I$ & $3 \times 10^{-100}$ & WP_014005418.1 & $\begin{array}{l}\text { Multidrug ABC transporter ATP-binding protein } \\
\text { [Collimonas fungivorans] }\end{array}$ & 0 & 1 & 0 & 1 \\
\hline$A B C B$ VIII & $1 \times 10^{-6}$ & WP_005919053.1 & $\begin{array}{l}\text { Excinuclease } \mathrm{ABC} \text { subunit } \mathrm{A} \text {, uvrA } \\
\text { [Pediococcus acidilactici] }\end{array}$ & 0 & 1 & 0 & 1 \\
\hline ABCB IX & $2 \times 10^{-43}$ & WP_008117112.1 & ABC transporter [Herbaspirillum sp. YR522] & 0 & 1 & 0 & 1 \\
\hline$A B C B I$ & $1 \times 10^{-112}$ & WP_014007698.1 & $\begin{array}{c}\text { Methionine ABC transporter ATP-binding protein } \\
\text { [Collimonas fungivorans] }\end{array}$ & 0 & 1 & 0 & 1 \\
\hline$A B C B$ II & $4 \times 10^{-78}$ & WP_027616274.1 & $\begin{array}{l}\text { ABC transporter ATP-binding protein } \\
\text { [Pseudomonas sp. URHB0015] }\end{array}$ & 0 & 1 & 0 & 1 \\
\hline$A B C B$ III & $4 \times 10^{-128}$ & WP_007878001.1 & $\begin{array}{l}\text { Peptide ABC transporter ATP-binding protein } \\
\text { [Herbaspirillum sp. CF444] }\end{array}$ & 0 & 1 & 0 & 1 \\
\hline$A B C B \times I$ & 0 & ЕКC24099.1 & $\begin{array}{c}\text { ATP-binding cassette sub-family B member } 8, \\
\text { mitochondrial [Crassostrea gigas] }\end{array}$ & 0.07 & $4.7 \times 10^{-11}$ & -0.41 & 0 \\
\hline
\end{tabular}


Table 1. Cont.

\begin{tabular}{|c|c|c|c|c|c|c|c|}
\hline \multirow{2}{*}{ Name } & \multirow{2}{*}{ Lowest $E$-Value } & \multirow{2}{*}{ Accession (E-Value) } & \multirow{2}{*}{ Description } & \multicolumn{2}{|c|}{ Adults DM/Adults Control } & \multicolumn{2}{|c|}{ Adults AZA/Adults Control } \\
\hline & & & & Fold Change & $p$-Value & Fold Change & $p$-Value \\
\hline$A B C B I V$ & $1 \times 10^{-53}$ & CCV01190.1 & $\begin{array}{c}\mathrm{ABCB} / \text { P-glycoprotein-like protein } \\
\text { [Mytilus galloprovincialis] }\end{array}$ & 0 & 1 & 0 & 1 \\
\hline$A B C C X V$ & 0 & XP_005496337.1 & $\begin{array}{l}\text { PREDICTED: multidrug resistance-associated protein } \\
\text { 4-like [Zonotrichia albicollis] }\end{array}$ & 0.78 & 0 & -0.43 & 0 \\
\hline$A B C B V$ & $2 \times 10^{-74}$ & KFM56907.1 & $\begin{array}{l}\text { Multidrug resistance protein } 1 \text { [Stegodyphus } \\
\text { mimosarum] }\end{array}$ & 0 & 1 & 0 & 1 \\
\hline$A B C C X I I$ & 0 & KDR17053.1 & $\begin{array}{l}\text { Multidrug resistance-associated protein } 7 \\
\text { [Zootermopsis nevadensis] }\end{array}$ & 0.28 & 0 & 0.28 & 0 \\
\hline$A B C C X I I I$ & 0 & XP_004342702.1 & $\begin{array}{l}\text { Multidrug resistance-associated protein } 3 \\
\text { [Capsaspora owczarzaki ATCC 30864] }\end{array}$ & 0.42 & 0 & -0.144 & 0 \\
\hline$A B C B X$ & $2 \times 10^{-24}$ & EFN74443.1 & $\begin{array}{l}\text { ATP-binding cassette sub-family B member 10, } \\
\text { mitochondrial [Camponotus floridanus] }\end{array}$ & NN & 0 & 0 & 1 \\
\hline$A B C C X$ & 0 & EFX68457.1 & $\begin{array}{l}\text { ATP-binding cassette, sub-family C, member } 4 \\
\text { [Daphnia pulex] }\end{array}$ & 2.08 & 0 & 0.151 & 0 \\
\hline $\begin{array}{l}A B C C \text { VII } \\
\text { DELTEX }\end{array}$ & $\begin{array}{l}2 \times 10^{-172} \\
8 \times 10^{-60}\end{array}$ & XP_002116818.1 & $\begin{array}{l}\text { ATP-dependent bile acid permease [Aedes aegypti] } \\
\text { Protein deltex [Acromyrmex echinatior] }\end{array}$ & $\begin{array}{l}1.76 \\
0.135\end{array}$ & $\begin{array}{l}0 \\
0\end{array}$ & $\begin{array}{c}0.116 \\
-0.007\end{array}$ & $\begin{array}{c}0 \\
6.95 \times 10^{-10}\end{array}$ \\
\hline FRINGE & $7 \times 10^{-96}$ & XP_002422797.1 & $\begin{array}{l}\text { Fringe glycosyltransferase, putative } \\
\text { [Pediculus humanus corporis] }\end{array}$ & 0.130 & $8.88 \times 10^{-11}$ & -0.531 & 0 \\
\hline Aph-1 & $3 \times 10^{-111}$ & ADD24087.1 & $\begin{array}{l}\text { Gamma-secretase subunit Aph-1 } \\
\text { [Lepeophtheirus salmonis] }\end{array}$ & 0.43 & $2.62 \times 10^{-05}$ & -0.55 & 0 \\
\hline GROUCHO1 & $\begin{array}{l}0 \\
0\end{array}$ & $\begin{array}{l}\text { BAN21009.1 } \\
\text { BAN21009.1 }\end{array}$ & Groucho [Riptortus pedestris] & $\begin{array}{c}0.01 \\
-0.29\end{array}$ & 0.48 & 0.541 & 0 \\
\hline $\begin{array}{l}\text { GROUCHO2 } \\
\text { HDAC }\end{array}$ & $\begin{array}{c}0 \\
2 \times 10^{-29}\end{array}$ & $\begin{array}{l}\text { BAN21009.1 } \\
\text { XP_001862395.1 }\end{array}$ & $\begin{array}{l}\text { Groucho [Riptortus pedestris] } \\
\text { Histone deacetylase [Culex quinquefasciatus] }\end{array}$ & $\begin{array}{l}-0.29 \\
-0.167\end{array}$ & $\begin{array}{l}0 \\
0\end{array}$ & $\begin{array}{l}0.57 \\
0.58\end{array}$ & $\begin{array}{l}0 \\
0\end{array}$ \\
\hline HDAC3 & $1 \times 10^{-158}$ & EFX81904.1 & $\begin{array}{l}\text { Putative histone deacetylase HDAC3 protein } \\
\text { [Daphia pulex] }\end{array}$ & 0.232 & 0 & 0.25 & 0 \\
\hline HDAC4 & $3 \times 10^{-148}$ & XP_001605910.2 & $\begin{array}{l}\text { PREDICTED: histone deacetylase } 4 \text {-like [Nasonia } \\
\text { vitripennis] }\end{array}$ & -0.752 & 0 & 0.39 & 0 \\
\hline HDAC6 & 0 & NP_001162760.1 & HDAC6, isoform D [Drosophila melanogaster] & -0.51 & 0 & $-1.0 \times 10^{-1}$ & 0 \\
\hline $\begin{array}{l}\text { NOTCH1 } \\
\text { NOTCH2 }\end{array}$ & $\begin{array}{l}0 \\
0\end{array}$ & $\begin{array}{l}\text { EFX77274.1 } \\
\text { AGT57827.1 }\end{array}$ & $\begin{array}{l}\text { NOTCH } 2 \text { [Daphnia pulex] } \\
\text { NOTCH [Euperipatoides rowelli] }\end{array}$ & $\begin{array}{c}0.609 \\
0.42\end{array}$ & $\begin{array}{l}0 \\
0\end{array}$ & $\begin{array}{l}0.114 \\
0.104\end{array}$ & $\begin{array}{l}0 \\
0\end{array}$ \\
\hline NOTCH3 & $1 \times 10^{-36}$ & EZA58452.1 & Neurogenic locus NOTCH protein [Cerapachys biroi] & -0.181 & 0 & -0.51 & 0 \\
\hline NUMB & $1 \times 10^{-106}$ & EZA52633.1 & Protein numb [Cerapachys biroi] & -0.75 & 0 & 0.03 & 0 \\
\hline PSEN & $2 \times 10^{-134}$ & EHJ71857.1 & Presenilin-like signal peptide peptidase & 0.391 & 0 & -0.085 & 0 \\
\hline SKIP & $1 \times 10^{-31}$ & AGM16247.1 & $\begin{array}{l}\text { [Danaus plexippus] } \\
\text { Even-skipped isoform } 2 \text { [Nasonia vitripennis] }\end{array}$ & $\mathrm{NN}$ & 0 & 0 & 1 \\
\hline
\end{tabular}


Table 2. (A) Survival rate of sea lice individuals exposed to deltamethrin and (B) azamethiphos.

\begin{tabular}{ccc}
\hline (A) Deltamethrin (ppb) & Female & Male \\
\hline 0 & 100 & 100 \\
1 & 53.3 & 13.3 \\
2 & 26.7 & 20.0 \\
3 & 26.7 & 0.0 \\
\hline (B) Azamethiphos (ppb) & Female & Male \\
\hline 0 & 100 & 100 \\
1 & 80 & 73.3 \\
3 & 53.3 & 40 \\
10 & 12.4 & 10 \\
30 & 0 & 0 \\
\hline
\end{tabular}

To determine if the delousing drugs simply shifted the global gene expression profile of the $\mathrm{NOTCH}$ and $\mathrm{ABC}$ pathways by advancing or delaying the response, the maximum abundance levels of mRNA transcripts were compared over a period post-delousing challenge. Transcript analyses highlighted significant, dose-dependent differences in specific mRNAs (Figure 2A,B). Notably, significant interactions were identified between mRNA pathways when evaluated after AZA and DM exposure. The observed differences in mRNA abundance were not a consequence of a temporal shift, but rather reflected specific drug-dependent increases in transcript abundances of the $A B C$ genes and NOTCH pathway (Figure 2A). This suggests increased transcription focus and functional specialization, as well as a strong effect of delousing drugs on these processes. In turn, this increased response indicates that $\mathrm{AZA}$ and DM drive modifications in the regulation of downstream NOTCH components, as well as in the mRNA abundances of $A B C$ genes, suggesting that $\mathrm{NOTCH} / \mathrm{ABC}$ regulation plays a role in drug resistance in Caligus species. Furthermore, the directional shift of transcripts regulated within NOTCH/ABC mRNAs was measured. The addition of DM as a variable showed that $70 \%$ of the transcripts within $\mathrm{ABC}$ clusters were directionally increased as compared to controls, and these transcripts were linked to increased abundance variation, signifying a change in functional NOTCH/ABC output (Figure 2B).
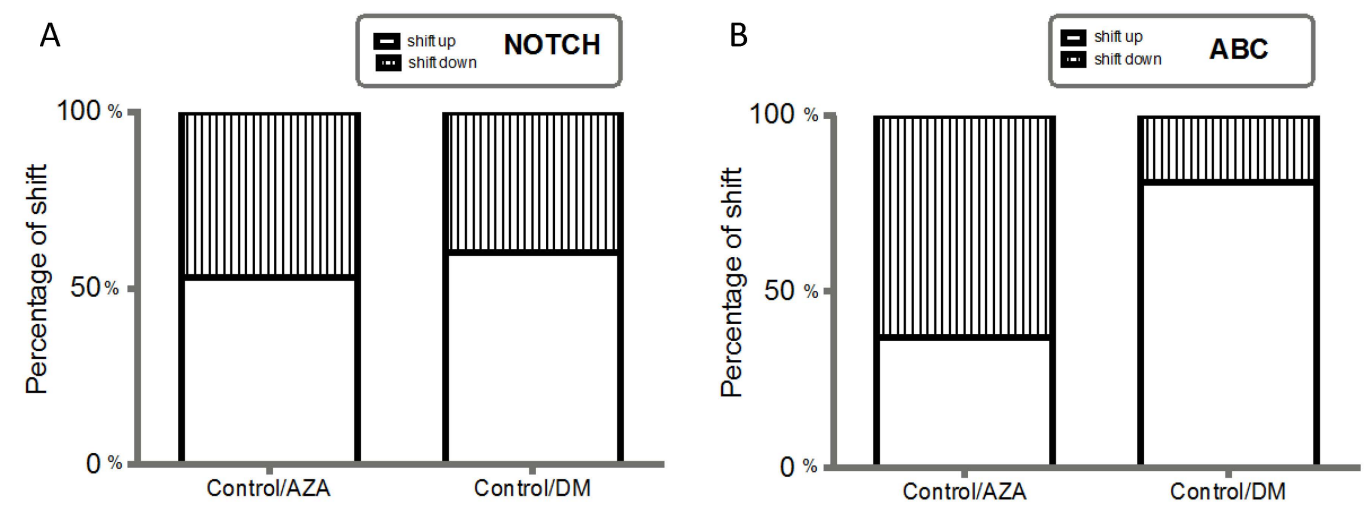

Figure 2. Regulation of NOTCH/ABC components. (A) Percentile directional shift (Control vs. Deltamethrin (DM)); (B) Percentile directional shift (Control vs. Azamethiphos (AZA)). Hatched and white bars represent down and upregulated transcripts, respectively, and percentile increases represent mean mRNA transcript abundance (\% increase or decrease, respectively) of representative regulatory pathways.

\subsection{Differentially Expressed Genes of the NOTCH Signaling Pathway from C. rogercresseyi}

Real time-qPCR was used to examine whether DM or AZA were able to trigger differences in the abundances of $\mathrm{ABC}$ mRNA related to the downstream $\mathrm{NOTCH}$ pathway or $\mathrm{ABC}$ transporters. The 
obtained results showed that both delousing drugs triggered an overall increase of gene expression and that these genes were differentially regulated in a dose-dependent manner (e.g., PSEN1 and GSEC). As shown in Figures 3 and 4 AZA only induced the expression of downstream NOTCH components depending on the sex. However, both treatments induced a weak response at $10 \mathrm{ppb}$ in males and females. DM induced a large increase of PSEN11, DELTEX, PSEN1EN, and GROUCHO, with maximum expression at $3 \mathrm{ppb}$ in males and between 1-2 ppb for females, with expression gradually decreasing in females until $3 \mathrm{ppb}$. AZA increased the expression of NOTCH pathway components, with maximum expression at a concentration of $3 \mathrm{ppb}$, decreased expression at $1 \mathrm{ppb}$, and nearly undetectable expression at $10 \mathrm{ppb}$ (Figure 4).
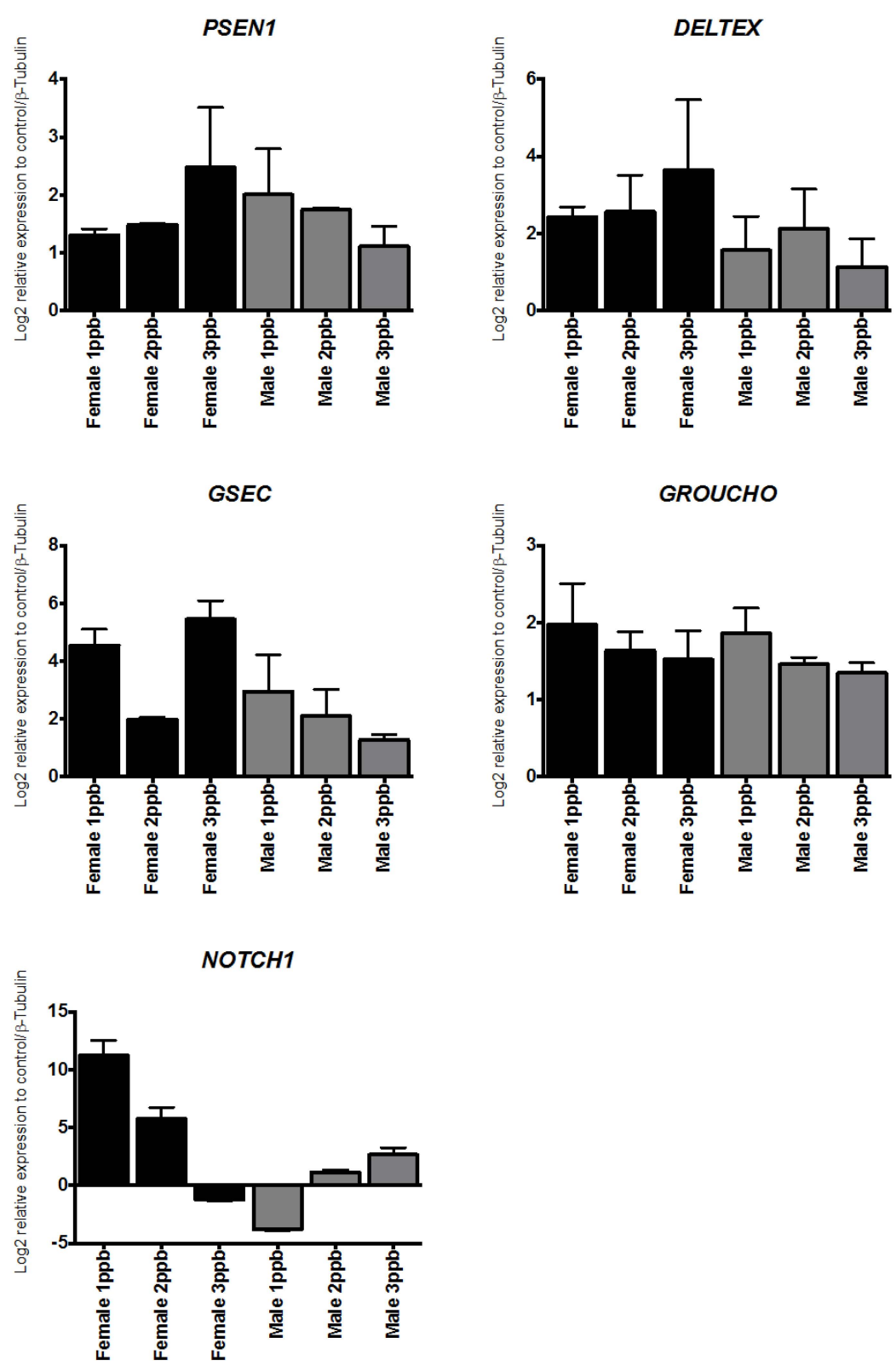

Figure 3. Transcriptional response of NOTCH signaling pathway components. Transcriptional response of NOTCH signaling pathway components in $C$. rogercresseyi exposed to deltamethrin. Each bar represents mean $( \pm \mathrm{SD})$ expression levels normalized to $\beta$-tubulin $(n=9)$. 


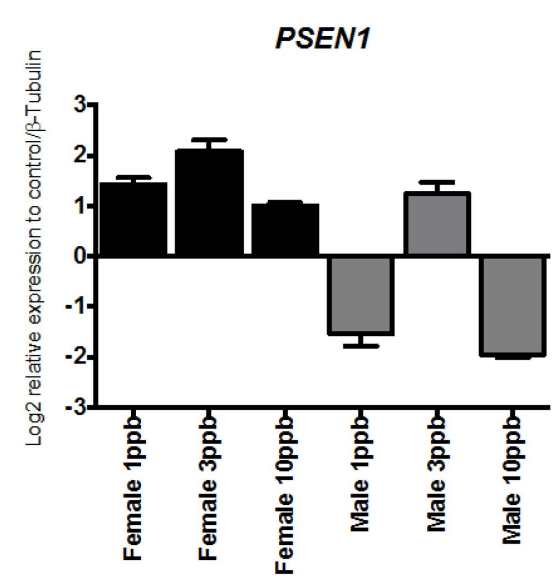

GSEC

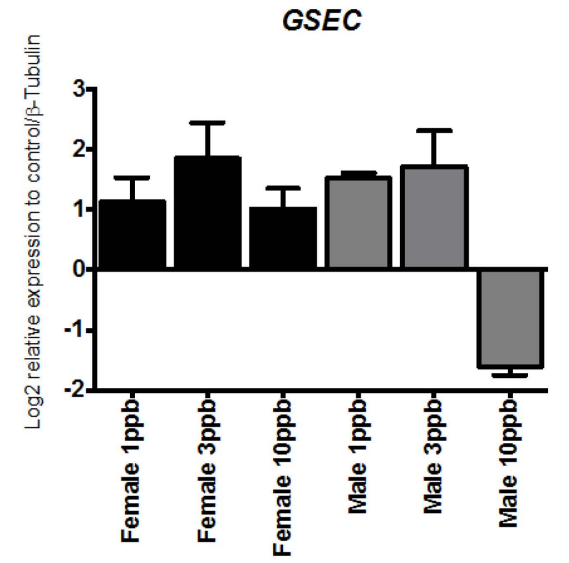

NOTCH1

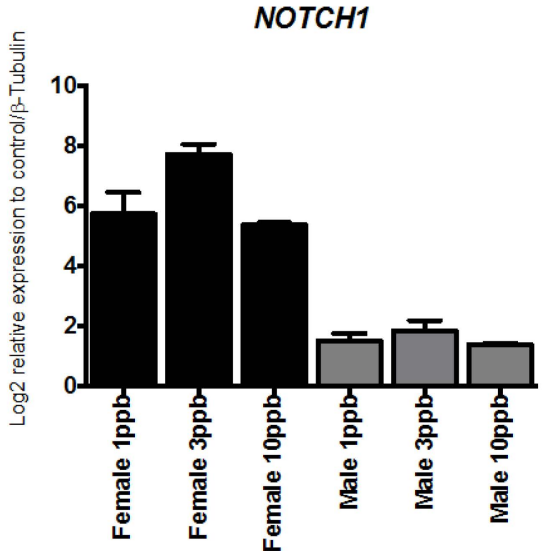

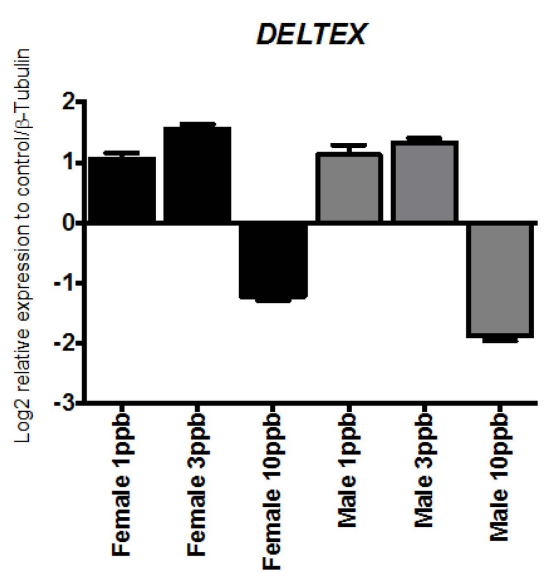

GROUCHO

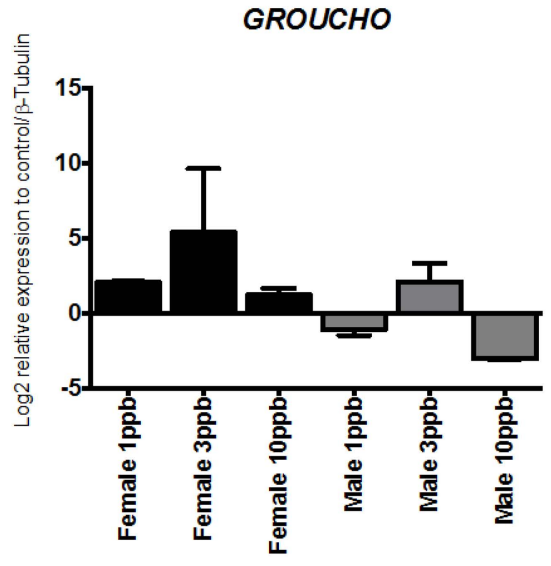

Figure 4. Transcriptional response of NOTCH signaling pathway components. Transcriptional response of NOTCH signaling pathway components in $C$. rogercresseyi exposed to azamethiphos. Each bar represents mean $( \pm \mathrm{SD})$ expression levels normalized to $\beta$-tubulin $(n=9)$.

Using RT-qPCR, both AZA and DM (1-3 or $10 \mathrm{ppb})$ promoted mRNA increases of the $A B C$ genes CXII, CIII, and BXII. Additionally, ABC transporters seemed to be highly influenced by AZA, with $A B C$ CXII, CIII and BXII gene expressions closely correlated to sex, mostly increased in males, but not to dose (Figure 5). In the DM group, the expression of $A B C$ transporters had a response opposite to that observed with AZA treatment. DM increased the mRNA levels of $A B C$ genes CXII, CXIII, and BXII with the three doses and for both sexes, in contrast to that observed with AZA. AZA triggered increased mRNA abundance, mainly in males, for $A B C$ BXII and CXIII, with females displaying maximum expression at 1-2 ppb, with decreasing expression until $3 \mathrm{ppb}$ (Figure 5). 
A
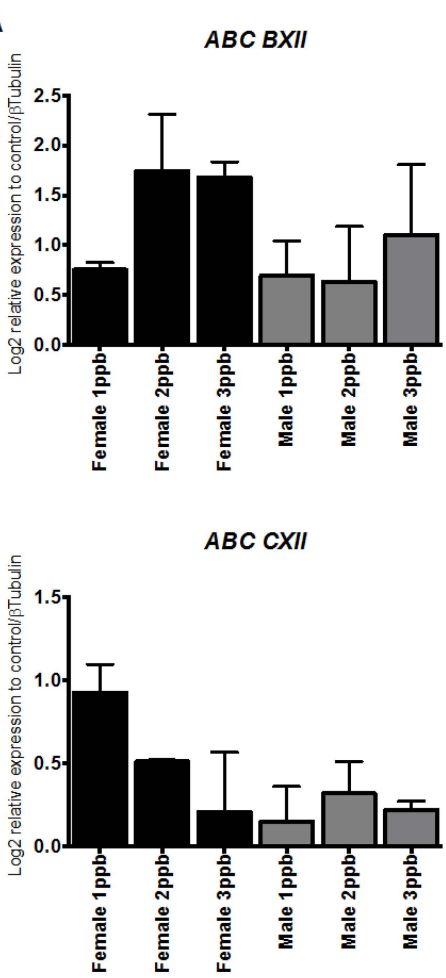

$A B C$ CXIII

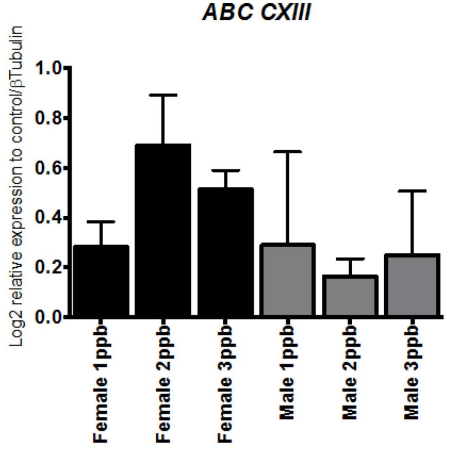

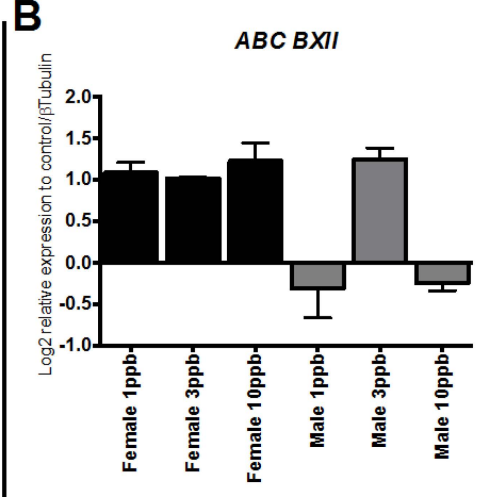

$A B C$ CXII

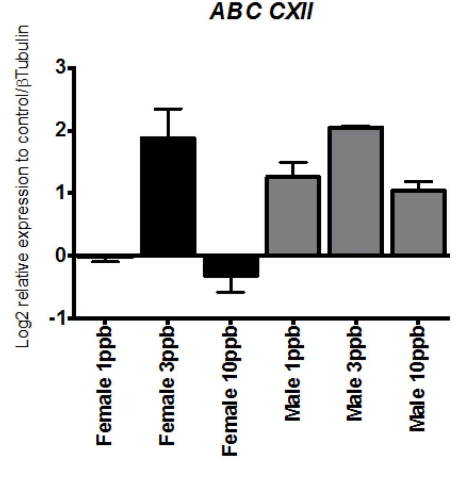

$A B C$ CXIII

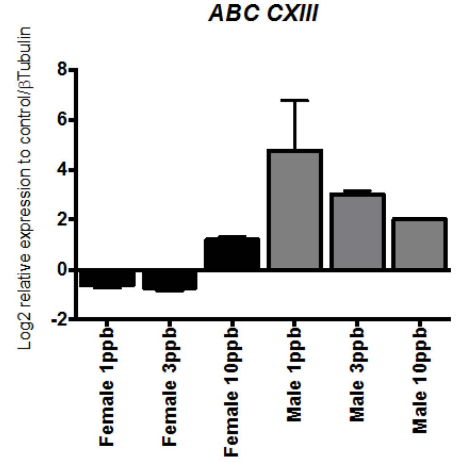

Figure 5. Transcriptional response of $\mathrm{ABC}$ membrane transporters in C. rogercresseyi exposed to two antiparasitics. (A) Deltamethrin; and (B) Azamethiphos. Each bar represents mean $( \pm \mathrm{SD})$ expression levels normalized to $\beta$-tubulin $(n=9)$.

\subsection{Principal Component Analysis (PCA)}

The global expression profiles of $C$. rogercresseyi exposed to the delousing drugs DM and AZA were compared. Transcripts were scored positively for reliable annotation among all samples. These transcripts were used for statistical analysis to find mRNAs with abundance levels that significantly differed between the two treatments. DeDaL was used to create a DDL layout for a group of C. rogercresseyi genes involved in the downstream NOTCH pathway. Hierarchal cluster analysis and PCA were applied to determine the contribution that each gene had in the response to treatment with DM and AZA.

The DeDaL-PCA Cytoscape plugin combined the classical and advanced data dimension reduction methods with the algorithms of network layout inside the Cytoscape environment. The genetic interactions between the analyzed genes using RT-qPCR and the corresponding epistatic profiles were selected from the global expression profile provided by RNA-seq. Definitions of the $\mathrm{NOTCH}$ pathway were taken from the KEGG database [27]. Figure 6A,B shows the differences between 
the standard organic and PCA-based DDL layouts for this small network of genetic interactions. These layouts were computed without double-centering the matrix data to take into account tendencies of genes to interact with a smaller or larger number of other genes, thereby estimating the effects that AZA and DM concentrations had on the mRNA abundance of NOTCH pathway components.

A

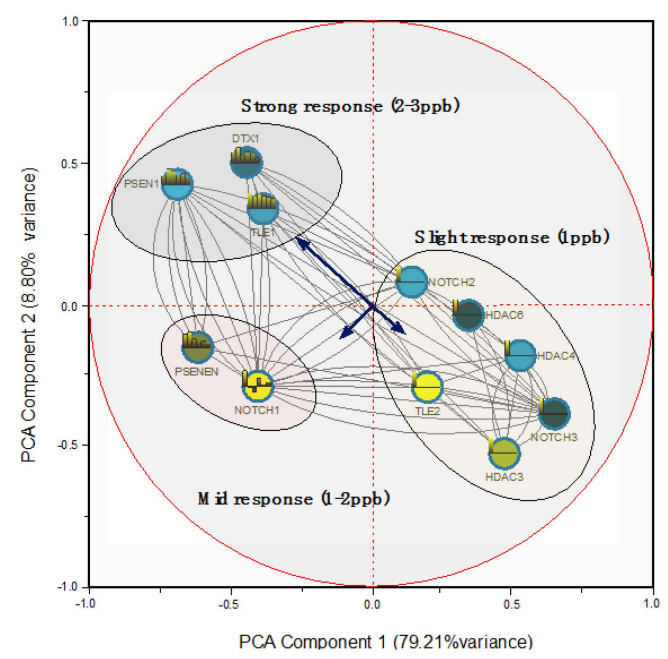

B

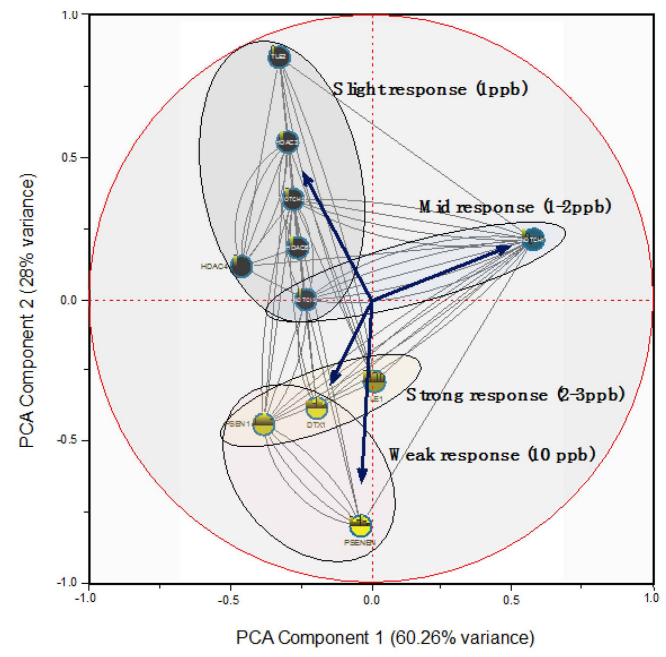

Figure 6. Interaction network between NOTCH/ABC genes involved in delousing drug treatments. Different node colors indicate distinct mRNA regulations during chemical exposure. Principal component analysis (PCA) was performed on the network-smoothed profile through DDL computation using an elastic map (elmap) algorithm for calculating the non-linear principal manifold. A factorial map of PCA was constructed for data from all commonly expressed transcripts in each pathway, represented as a point for each delousing drug, (A) Deltamethrin and (B) Azamethiphos. The coordinates of the arrow on the ordination axes represent the values of Pearson's correlation coefficient between the gene expression and the drug concentration used in each treatment. The percentage of variance explained by each principal component is indicated in parentheses.

Both PCAs (Figure 6A,B) denoted the differences between delousing drugs, where the concentrations used in each treatment could easily be separated, in addition to identifying a threshold concentration used for the treatments. First, the local NOTCH genes TLE2, HDAC3, NOTCH2, and NOTCH1 had distinct positions in each PCA layout. Second, PCA-based DDL roughly grouped the genes according to involvement in each drug concentration. The PCA revealed two main specific global scale patterns based on the different responses of $C$. rogercresseyi when treated with DM or AZA (Table 2). The correlated variability pattern of the expressed genes was prominently different between $\mathrm{DM}$ and AZA. In addition to the global separation that defined the responses to the two drugs, an inverse sex-dependent pattern was found when comparing the different associated genes (Figure 6A,B). For example, AZA concentrations had a strong effect on the NOTCH pathway components (Figure 6B). Moreover, some genes, such as PSEN1EN, PSEN11, and DELTEX, showed a weak expression pattern at a concentration of $10 \mathrm{ppb}$ (i.e., negative threshold of activation). This was in contrast to the strong response triggered at concentrations of 1-3 ppb. In both treatments, the two principal factors explained close to $90 \%$ of expression variability (Figure 6A,B), and a similar dose-dependent effect of each treatment on the expression profile of the downstream NOTCH pathway was suggested.

\subsection{Single Nucleotide Polymorphisms (SNPs) Mining}

A total of 54 SNPs were identified in NOTCH signaling components in C. rogercresseyi for both sexes (Table 3). In NOTCH components, the identified variations were synonymous or present in the $3^{\prime}$ or $5^{\prime}$ UTR (Table 3). Just three contigs presented SNPs in the open reading frame and $3^{\prime} \mathrm{UTR}$. 
For contigs annotated for DELTEX, 11 SNPs were related with synonymous variations while three were non-synonymous. Four SNPs were present in the open reading frame and $3^{\prime} U T R$. Despite these results, more studies are necessary to determine the function of non-synonymous variations in NOTCH components, as well as the possible association of these with delousing drug resistance.

Table 3. List of single nucleotide polymorphisms (SNPs) identified in NOTCH pathway genes in adult C. rogercresseyi.

\begin{tabular}{|c|c|c|c|c|}
\hline Name & Consensus Position & Allele & Frequency & Substitution \\
\hline \multirow{18}{*}{ DELTEX } & 3468 & $\mathrm{~A} / \mathrm{G}$ & 31.30 & $3^{\prime}$ UTR \\
\hline & 3079 & G/A & 30.94 & $3^{\prime} \mathrm{UTR}$ \\
\hline & 3067 & $\mathrm{G} / \mathrm{T}$ & 26.21 & $3^{\prime} \mathrm{UTR}$ \\
\hline & 2784 & $\mathrm{G} / \mathrm{T}$ & 31.03 & Synonymous \\
\hline & 2698 & $\mathrm{C} / \mathrm{T}$ & 20.88 & Synonymous \\
\hline & 2679 & $\mathrm{~T} / \mathrm{C}$ & 32.35 & Synonymous \\
\hline & 2616 & $\mathrm{~T} / \mathrm{C}$ & 43.70 & Synonymous \\
\hline & 2434 & $\mathrm{~A} / \mathrm{G}$ & 46.15 & Non synonymous \\
\hline & 2181 & $\mathrm{~T} / \mathrm{C}$ & 47.35 & Synonymous \\
\hline & 1853 & $\mathrm{C} / \mathrm{A}$ & 21.05 & Non synonymous \\
\hline & 1659 & $\mathrm{~A} / \mathrm{C}$ & 41.38 & Non synonymous \\
\hline & 1301 & $\mathrm{~T} / \mathrm{C}$ & 31.39 & Synonymous \\
\hline & 1116 & A/G & 34.81 & Synonymous \\
\hline & 1038 & $\mathrm{C} / \mathrm{T}$ & 27.01 & Synonymous \\
\hline & 987 & $\mathrm{G} / \mathrm{A}$ & 48.63 & Synonymous \\
\hline & 954 & $\mathrm{G} / \mathrm{A}$ & 34.18 & Synonymous \\
\hline & 927 & $\mathrm{~A} / \mathrm{G}$ & 38.46 & Synonymous \\
\hline & 489 & A/G & 25.50 & 5'UTR \\
\hline \multirow{4}{*}{ FRINGE } & 133 & $\mathrm{~T} / \mathrm{A}$ & 54.55 & $5^{\prime} \mathrm{UTR}$ \\
\hline & 940 & $\mathrm{C} / \mathrm{T}$ & 29.27 & Non synonymous \\
\hline & 979 & $\mathrm{~A} / \mathrm{C}$ & 49.04 & Non synonymous \\
\hline & 1260 & $\mathrm{~T} / \mathrm{C}$ & 45.45 & $5^{\prime}$ UTR \\
\hline \multirow{3}{*}{$A P H-1$} & 829 & $\mathrm{~T} / \mathrm{C}$ & 42.86 & Synonymous \\
\hline & 793 & $\mathrm{~T} / \mathrm{G}$ & 48.06 & Synonymous \\
\hline & 671 & $\mathrm{~T} / \mathrm{C}$ & 21.16 & Synonymous \\
\hline \multirow{4}{*}{ GROUCHO1 } & 1754 & $\mathrm{C} / \mathrm{T}$ & 25.73 & Synonymous \\
\hline & 1430 & $\mathrm{~T} / \mathrm{C}$ & 23.83 & Synonymous \\
\hline & 1202 & G/A & 20.94 & Synonymous \\
\hline & 266 & $\mathrm{G} / \mathrm{A}$ & 35.27 & Synonymous \\
\hline \multirow{8}{*}{ HDAC6 } & 3792 & $\mathrm{~T} / \mathrm{C}$ & 45.71 & $3^{\prime} \mathrm{UTR}$ \\
\hline & 3433 & $\mathrm{C} / \mathrm{T}$ & 41.89 & $3^{\prime} \mathrm{UTR}$ \\
\hline & 3381 & $\mathrm{C} / \mathrm{G}$ & 34.60 & $3^{\prime} \mathrm{UTR}$ \\
\hline & 3156 & $\mathrm{G} / \mathrm{T}$ & 38.60 & $3^{\prime} \mathrm{UTR}$ \\
\hline & 2586 & $\mathrm{~T} / \mathrm{C}$ & 39.13 & Synonymous \\
\hline & 2199 & $\mathrm{~T} / \mathrm{C}$ & 33.71 & Synonymous \\
\hline & 681 & $\mathrm{~A} / \mathrm{C}$ & 21.52 & Synonymous \\
\hline & 600 & $\mathrm{~T} / \mathrm{C}$ & 24.69 & Synonymous \\
\hline \multirow{11}{*}{ NOTCH1 } & 10732 & $\mathrm{C} / \mathrm{A}$ & 48.88 & Synonymous \\
\hline & 3509 & G/A & 24.35 & Non synonymous \\
\hline & 3067 & $\mathrm{C} / \mathrm{T}$ & 26.40 & Synonymous \\
\hline & 2890 & $\mathrm{~A} / \mathrm{G}$ & 20.35 & Synonymous \\
\hline & 2758 & $\mathrm{C} / \mathrm{T}$ & 41.67 & Synonymous \\
\hline & 2491 & $\mathrm{G} / \mathrm{C}$ & 28.57 & Synonymous \\
\hline & 2035 & $\mathrm{~A} / \mathrm{C}$ & 30.59 & Synonymous \\
\hline & 1468 & $\mathrm{G} / \mathrm{T}$ & 36.89 & Synonymous \\
\hline & 400 & $\mathrm{C} / \mathrm{A}$ & 44.83 & Synonymous \\
\hline & 281 & $\mathrm{~T} / \mathrm{A}$ & 25.93 & $5^{\prime} \mathrm{UTR}$ \\
\hline & 251 & $\mathrm{C} / \mathrm{T}$ & 31.37 & $5^{\prime} \mathrm{UTR}$ \\
\hline $\mathrm{NOTCH} 2$ & 373 & $\mathrm{~A} / \mathrm{C}$ & 21.32 & Non synonymous \\
\hline \multirow{3}{*}{ PSEN } & 1463 & $\mathrm{~T} / \mathrm{C}$ & 48.50 & $3^{\prime} \mathrm{UTR}$ \\
\hline & 797 & $\mathrm{~T} / \mathrm{C}$ & 21.07 & Non synonymous \\
\hline & 352 & $\mathrm{~T} / \mathrm{G}$ & 24.98 & Non synonymous \\
\hline NUMB & 51 & $\mathrm{G} / \mathrm{A}$ & 27.27 & Synonymous \\
\hline
\end{tabular}




\section{Discussion}

Several studies have identified DM and AZA as effective pesticides in the control of caligidosis, triggering, among other processes, the generation of reactive oxygen species [28]. However, little information is available about the effects of these pesticides on the transcriptomic response of the parasite and the correlation of this response with drug resistance. This study is the first to characterize the NOTCH signaling pathway and $\mathrm{ABC}$ transporters in C. rogercresseyi and the regulation of these under treatment with pesticides.

Different delousing drugs promote changes in the transcriptional profile in the sea lice L. salmonis and C. rogercresseyi $[4,27,29,30]$. By systematically dissecting the impact and combination of treatment parameters (sex and dose), the present data revealed a significant remodeling of the C. rogercresseyi transcriptome, thus emphasizing the strong effects of delousing drugs. In C. rogercresseyi, transcriptomic profile modifications occur in response to developmental stages, reproductive phases, or the maintenance of steady state transcriptional activity [26,28-30]. In sea lice, exposure to delousing drugs such as DM or AZA results in a shift from a steady state to a functional reactive state (i.e., production of reactive oxygen species) through the secretion of peroxinectin [28-30].

The present study demonstrated a strong response to delousing chemicals by the entire transcriptome, as well as by key molecular process closely linked with pesticide resistance, such as in the NOTCH/ABC pathways. RNA-seq analysis identified a dose-dependent, differential regulation of mRNAs following exposure to the delousing drugs AZA and DM. A similar phenomenon was observed for response magnitude; however, in most cases, DM triggered higher expressions of NOTCH pathway components compared to AZA exposure. Interestingly, $10 \mu \mathrm{g} / \mathrm{mL}$ was the threshold AZA concentration needed to activate downstream NOTCH components. These data support previous research on delousing chemicals, which found similar activation thresholds [28]. Other studies have closely linked the transcriptomic response of L. salmonis and C. rogercresseyi with the generation of resistance to emamectin benzoate, showing that P-glycoprotein gene expression slightly increases after $24 \mathrm{~h}$ of exposure to $10 \mathrm{ppb}$ of this avermectin [21,31]. Together, these results suggest that although there are differences in drug compositions, a common reaction threshold to delousing drugs exists.

Considering this, the present analyses denote the importance of concentration and sex on response intensity (fold-change) at a molecular level. Varied sensitivity is likely conferred by the participation of different $\mathrm{ABC}$ genes and NOTCH receptors in the drug-Caligus interaction, and/or the accumulative signaling intensity (i.e., threshold) of the group of receptors involved in the reaction mechanism. Integrative analysis of transcriptome data through computational and analytical approaches further supports this observation by extending the interpretative value of a one-dimensional gene list into regulatory modules and interaction networks [32]. Comparison of drug-reaction transcriptomes at different levels, including of pathway-concentration interactions and PCA-module analyses, demonstrated significantly different modifications in the magnitude and intensity of measured responses to the delousing drugs.

Transcriptional analysis showed that AZA and DM were able to trigger a minor increase in the mRNA abundances of PSEN1 and APH-1. Presenilin-1 is a catalytic subunit of the $\gamma$-secretase complex and has been principally described as a modifiable component of the NOTCH signaling pathway [33]. The slight changes in the mRNA abundances of both subunits suggest that NOTCH cleavage cannot take place. Moreover, the antiparasitics seemed to affect the negative regulator of the NOTCH receptor by triggering changes (downregulation) the mRNA abundance of NUMB (see Figure 1 and Table 1). This protein has a phosphotyrosine-binding domain in the N-terminal and is linked by this domain to the cell membrane location that contributes to the role of NUMB in the control of intracellular NOTCH trafficking $[21,34]$.

Additionally, RNA-seq analysis identified two proteins of the NOTCH repressor complex, HDAC and GROUCHO. GROUCHO is a protein with five domains, two of which are highly conserved at the $\mathrm{N}$ - and C-terminals (Gln and Trp-Asp). These domains have essential functions in interacting with a variety of DNA-binding proteins and in mediating the transcriptional switch-off of the downstream 
NOTCH pathway [35]. Particularly, HDAC is an enzyme with a multiprotein-complex that suppresses the CSL factor of NOTCH receptors [36].

In the present study, HDAC showed differential and contrasting responses to each drug; DM promoted a slight increase in HDAC mRNA abundance while AZA triggered a high increase in HDAC mRNA. These results suggest a repressor role of the CSL transcription factor in the presence of organophosphates. The ABC transporters were also promoted during AZA exposure. These results are in line with a previous report by Cho et al. [23], showing that components of the NOTCH signaling pathways are closely associated with the $\mathrm{ABC}$ transporters and that both are stimulated during drug exposure [23,37]. Collectively, these data suggest a significant and similar effect of both chemicals, in addition to indicating that frequent organophosphate and pyrethroid use could be promoting parasite resistance through the inhibition of $\mathrm{NOTCH} / \mathrm{ABC}$ gene components.

Interestingly, generalized transporter-responsive transcriptional changes were strongly evident until the dose of the organophosphate or pyrethroid was increased. As detailed above, the prime candidates in emerging drug resistance are genes involved in the ABC and NOTCH signaling pathways. Indeed, the current results support the hypothesis that treatment drugs have dose-dependent effects on individuals, such as with an upregulation of mRNAs related to inhibitory components of the $\mathrm{NOTCH} / \mathrm{ABC}$ genes. The interactions within this essential regulation-receptor system could play a key role in sea lice drug resistance $[9,38]$ such as observed for the effect of AZA and DM on cytochrome P450 [10].

Multiple mRNA transporter-related components linked to apoptosis, mitochondrial transport, oxidative stress, and glycolysis are affected by organophosphates and pyrethroids. A significant body of work describes delousing drug-induced cellular toxicity [13-15,33,39]. This is in addition to previous studies that have shown organophosphates and pyrethroids capable of causing mitochondrial oxidative stress in various invertebrate species [6,28]. However, little information is available on NOTCH/ABC mRNA regulation and the putative role of this pathway in pesticide resistance. It is possible that treatment-induced mRNA regulation is restricted in terms of the drugs and concentrations used. Therefore, the presented transcriptome signaling for the $\mathrm{NOTCH} / \mathrm{ABC}$ pathway is highly significant in relation to the whole transcriptomic response of parasites exposed to delousing drugs. Interactome analysis showed that DM exposure promoted strong transcriptional signaling indicative of inhibitory components of the NOTCH/ABC pathway.

\section{Materials and Methods}

\subsection{Experimental Design and High-Throughput Transcriptome Sequencing}

From a recent study by our group, Illumina sequencing data for C. rogercresseyi challenged with DM and AZA were obtained from the Sequence Read Archive (Acc. No. SRX864101) [25]. Briefly, adult $C$. rogercresseyi were obtained from a commercial farm located in Puerto Montt, Chile. Individuals were transported on ice to the laboratory and maintained with a constant water flow at $12{ }^{\circ} \mathrm{C}$ and gentle aeration until the bioassays. The samples were separated into four glass containers: one control and three experimental. The bioassays were performed according to the procedures described by the SEARCH Consortium [26]. Transcriptome sequencing was conducted in unchallenged (control) C. rogercresseyi and in C. rogercressey challenged with DM (AlphaMax ${ }^{\circledR} 1,2,3 \mathrm{ppb}$ ) and AZ (Bayer ${ }^{\circledR}$ 1, 3, $10 \mathrm{ppb}$ ). Thirty sea lice adults (15 females and 15 males) were exposed to each concentration of DM and AZA in petri plates containing $50 \mathrm{~mL}$ of seawater. Each experiment was performed in triplicate. The exposure period to either DM or AZA was 40 and $30 \mathrm{~min}$, respectively. During exposure, salmon lice were maintained at $12{ }^{\circ} \mathrm{C}$. After $24 \mathrm{~h}$, the organisms were fixed in RNAlater ${ }^{\circledR}$ RNA Stabilization Reagent (Ambion ${ }^{\circledR}$, Life Technologies ${ }^{\mathrm{TM}}$, Carlsbad, CA, USA) and stored at $-80^{\circ} \mathrm{C}$ until subsequent RNA extraction. The protocols for bioassays were performed according to the SEARCH Consortium [26]. Following DM (2 ppb) and AZA (3 ppb) exposure, twenty randomly 
selected individuals per concentration and drug were pooled. The drugs concentrations (DM, $2 \mathrm{ppb}$ and $\mathrm{AZA}, 3 \mathrm{ppb}$ ) were selected by the transcriptomic performance shown in previous bioassays.

Total RNA was extracted from three pools of individuals by treatment using the RiboPure ${ }^{\mathrm{TM}}$ Kit (Ambion ${ }^{\circledR}$, Life Technologies ${ }^{\mathrm{TM}}$ ) following the manufacturer's instructions. Quantity, purity, and quality of isolated RNA were measured in the TapeStation 2200 (Agilent Technologies Inc., Santa Clara, CA, USA) using the R6K Reagent Kit according to the manufacturer's instructions; samples with RIN over 8.0 were used for library preparation. Three biological replicates per pool (3 control, 3 DM, and 3 AZA) were used to construct the libraries. Subsequently, double-stranded cDNA libraries were constructed using the TruSeq RNA Sample Preparation Kit v2 (Illumina ${ }^{\circledR}$ ). Libraries with mean length peaks above $290 \mathrm{ppb}$ were used for sequencing and were quantified by qPCR using the Library Quantification Kit Illumina/Universal (Kappa, San Diego, CA, USA) according to the manufacturer's instructions; each sample pool was sequenced using MiSeq (Illumina ${ }^{\circledR}$, San Diego, CA, USA).

\subsection{Identification of Putative NOTCH Signaling Pathway Transcripts and SNPs Mining}

$\mathrm{NOTCH}$ signaling pathway transcripts were identified from the cDNA library of C. rogercresseyi [27]. The pathway components described for the mosquito Anopheles gambiae, deposited in the KEGG Pathway database, were used as a model to characterize the NOTCH signaling pathway of $C$. rogercresseyi. Contigs were annotated using the tBlastx algorithm from an enrichment crustacean EST-database (NCBI) with a cutoff $E$-value of $1 \times 10^{-5}$. The identified structural motifs of NOTCH-like receptors were analyzed using the online ScanProsite tool. Using the assembly obtained from all identified NOTCH signaling pathway genes, SNPs mining was performed using the Genomics Workbench v8.1 software (CLC Bio., Aarhus, Denmark). The parameters used were as follows: window length $=11$, maximum gap and mismatch count $=2$, minimum average quality of surrounding bases $=15$, minimum quality of central base $=20$, maximum coverage $=100$, minimum coverage $=8$, minimum variant frequency $(\%)=35$, and maximum expected variations (ploidy) $=2$.

\subsection{RNA-seq Analysis Hierarchical Cluster Analysis}

Sequencing data analysis was performed using the CLC Genomics Workbench software (CLC bio). Raw reads were filtered by quality and adapter/index trimmed. CLC bio's de novo assembly algorithm was used to create a contig list from previously filtered reads using a mismatch cost $=2$, insertion cost $=3$, deletion cost $=3$, length fraction $=0.8$, similarity fraction $=0.8$, and a minimum contig length $=250$. Finally, 411 contigs were adjusted by mapped reads, and end gaps were treated as mismatches. Expression values were estimated as reads per kilobase of exon model per million mapped reads and then normalized to the total number of assembled contigs, using state numbers in reads per 1,000,000. This normalized the number of reads to the size of assembled contigs and allowed for assessing the transcripts that were upregulated among different groups. Hierarchical clustering was performed using the Euclidean distance matrix and complete linkage method, while the Manhattan metric distance was used for hierarchical cluster analysis. Analyses were conducted in the Cluster3/TreeView open software (3.0, Palo Alto, CA, USA).

\subsection{Primer Design and Quantitative Real-Time Polymerase Chain Reaction Assay}

Contig sequences annotated to NOTCH, PSEN1, DELTEX, Aph -1, ABC and GROUCHO for C. rogercresseyi were used as a template for primer design with the Primer3 Tool included in the Geneious Pro software version 8.0 [40] (the primer efficiencies are shown in Table S1). The qPCR runs were performed with StepOnePlus ${ }^{\mathrm{TM}}$ (Applied Biosystems ${ }^{\circledR}$, Life Technologies) using the comparative $\Delta \mathrm{Ct}$ method. $\beta$-tubulin was selected as the housekeeping gene due to its stable value as inferred through the NormFinder algorithm. The other housekeeping genes assayed were elongation factor alpha and beta actin. Each reaction was conducted with a volume of $10 \mu \mathrm{L}$ using the Maxima ${ }^{\circledR}$ SYBR Green/ROX qPCR Master Mix (Thermo Scientific). The amplification cycle was as follows: $95^{\circ} \mathrm{C}$ for $10 \mathrm{~min}, 40$ cycles at $95^{\circ} \mathrm{C}$ for $15 \mathrm{~s}$, and $60^{\circ} \mathrm{C}$ for $1 \mathrm{~min}$, followed by a disassociation 
curve under these same conditions. The data obtained were analyzed through the Kruskal-Wallis test with Statistica software (Version 7.0, StatSoft, Inc.). Statistically significant differences were accepted with a $p<0.05$.

\subsection{Interactome, Principal Components, and Statistical Analyses}

Complementary analysis was conducted with the ClusterMaker Cytoscape plugin [41] using the Markov Cluster algorithm to search protein-protein interaction network modules derived from tandem affinity purification/mass spectrometry. This approach clustered the network into modules based on purification enrichment score to indicate the strength of node association and provide a fixed set of genes with high protein-protein affinity (interactome cluster nodes). Principal component analysis using the Gene Ontology package showed two-dimensional views, retrieved by the DeDaL plugin of Cytoscape [42], that were used to visualize the relatedness of all RNA-seq samples. All $p$-values were adjusted with a false discovery rate correction for multiple testing by the Benjamini-Hochberg method [43]. All genes with false discovery rate-corrected $p$-values $<0.05$ were considered significant. The expression of genes found to be significantly different between both treatments were further characterized by a hierarchical clustering analysis. Hierarchical clustering was based on the expression pattern across the sampled population, thereby identifying clusters of genes with common expression profiles. Sample variances were homogeneous (normal distribution). The principal components were computed in DeDaL using singular value decomposition, a method allowing the use of missing data values without pre-imputation, as described in Gorban and Zinovyev [44]. Data points containing more than $20 \%$ of missing values were filtered from the analysis. DeDaL computes the first 10 principal components if there are more than 10 data points, and $k$ principal components if there are $\mathrm{k}+1$ data points $(k<10)$. After computing the principal components, DeDaL reported the amount of variance explained by each of the principal components. DeDaL is the first method that permits constructing biological network layouts from high-throughput data using Cytoscape.

\section{Conclusions}

In conclusion, this study suggests that delousing drugs may increase the activity of inhibitory mRNA components, thereby promoting inhibitory NOTCH output signaling pathways. This study is the first to describe a correlated modulation of NOTCH signaling pathways and $\mathrm{ABC}$ transporter genes through the use of DM and AZA in C. rogerresseyi. Increasing chemicals concentrations were correlated with increased NOTCH mRNA expression, leading to interaction with ABC genes. Analyses emphasized that the key functions of $\mathrm{NOTCH} / \mathrm{ABC}$ components were in regulating distinct phases of the delousing drug-response in C. rogercresseyi. It is likely that these components could be related to resistance modifications resulting from the frequent use of organophosphates and pyrethroids. In insects, the toxic effects of antiparasitics are well established, and the present results extend upon previous observations in sea lice species, in addition to suggesting that frequent delousing drug exposure promotes interactions with $\mathrm{NOTCH} / \mathrm{ABC}$ genes (upregulation). However experimental studies are needed to elucidate the involvement of $A B C$ transporters to pyrethroid or organophosphate resistance in C. rogercresseyi.

Supplementary Materials: Supplementary materials can be found at http://www.mdpi.com/1422-0067/ 17/5/304/s1.

Acknowledgments: This work was supported by FONDAP (15110027) awarded by CONICYT-Chile.

Author Contributions: Cristian Gallardo-Escárate, Jaqueline Chávez-Mardones and Valentina Valenzuela-Muñoz conceived and designed the experiments; Jaqueline Chávez-Mardones performed the experiments; Sebastian Boltaña, Valentina Valenzuela-Muñoz, Jaqueline Chávez-Mardones analyzed the data; Cristian Gallardo-Escárate contributed reagents/materials/analysis tools; Sebastian Boltaña and Cristian Gallardo-Escárate wrote the paper.

Conflicts of Interest: The authors declare no conflict of interest. 


\section{Abbreviations}

$\begin{array}{ll}\text { ABC } & \text { ATP-binding cassettes } \\ \text { AZA } & \text { azamethiphos } \\ \text { CSL } & \text { CBF1/RBP-Jk/Suppressor of Hairless/LAG-1 } \\ \text { DM } & \text { deltamethrin } \\ \text { HDAC } & \text { histone deacetylase } \\ \text { NIC } & \text { intracellular C-terminal fragment of NOTCH } \\ \text { PCA } & \text { principal components analysis } \\ \text { PSEN1 } & \text { presenilin-1 } \\ \text { SNPs } & \text { single nucleotide polymorphisms }\end{array}$

\section{References}

1. Pike, A.W.; Wadsworth, S.L. Sealice on salmonids: Their biology and control. Adv. Parasitol. 2000, 44, 232-337.

2. Gonzalez, L.; Carvajal, J.; George-Nascimento, M. Differential infectivity of Caligus flexispina (Copepoda, Caligidae) in three farmed salmonids in Chile. Aquaculture 2000, 183, 13-23. [CrossRef]

3. Bravo, S.; Silva, M.; Monti, G. Efficacy of emamectin benzoate in the control of Caligus rogercresseyi on farmed Atlantic salmon (Salmo salar L.) in Chile from 2006 to 2007. Aquaculture 2012, 364-365, 61-66. [CrossRef]

4. Helgesen, K.; Bravo, S.; Sevatdal, S.; Mendoza, J.; Horsberg, T. Deltamethrin resistance in the sea louse Caligus rogercresseyi (Boxhall and Bravo) in Chile: Bioassay results and usage data for antiparasitic agents with references to Norwegian conditions. J. Fish Dis. 2014, 37, 877-890. [CrossRef] [PubMed]

5. Sevatdal, S.; Copley, L.; Wallace, C.; Jackson, D.; Horsberg, T. Monitoring of the sensitivity of sea lice (Lepeophtheirus salmonis) to pyrethroids in Norway, Ireland and Scotland using bioassays and probit modelling. Aquaculture 2005, 244, 19-27. [CrossRef]

6. Sevatdal, S.; Horsberg, T. Determination of reduced sensitivity in sea lice (Lepeophtheirus salmonis Krøyer) against the pyrethroid deltamethrin using bioassays and probit modelling. Aquaculture 2003, 218, 21-31. [CrossRef]

7. Gallardo-Escarate, C.; Valenzuela-Munoz, V.; Nunez-Acuna, G. RNA-Seq analysis using de novo transcriptome assembly as a reference for the salmon louse Caligus rogercresseyi. PLoS ONE 2014, 9. [CrossRef]

8. Dermauw, W.; van Leeuwen, T. The ABC gene family in arthropods: Comparative genomics and role in insecticide transport and resistance. Insect Biochem. Mol. 2014, 45, 89-110. [CrossRef] [PubMed]

9. Simmons, J.; D'Souza, O.; Rheault, M.; Donly, C. Multidrug resistance protein gene expression in Trichoplusia ni caterpillars. Insect Biochem. Mol. Biol. 2013, 22, 62-71. [CrossRef] [PubMed]

10. Bariami, V.; Jones, C.; Poupardin, R.; Vontas, J.; Ranson, H. Gene amplification, ABC transporters and cytochrome P450s: Unraveling the molecular basis of pyrethroid resistance in the dengue vector, aedes aegypti. PLoS Negl. Trop. Dis. 2012, 6. [CrossRef] [PubMed]

11. Kopan, R.; Ilagan, M.X.G. The Canonical Notch Signaling Pathway: Unfolding the Activation Mechanism. Cell 2009, 137, 216-233. [CrossRef] [PubMed]

12. Andersson, E.R.; Sandberg, R.; Lendahl, U. Notch signaling: Simplicity in design, versatility in function. Development 2011, 138, 3593-3612. [CrossRef] [PubMed]

13. Espinoza, I.; Miele, L. Notch inhibitors for cancer treatment. Pharmacol. Ther. 2013, 139, 95-110. [CrossRef] [PubMed]

14. Choi, Y.I.; Jeon, S.H.; Jang, J.; Han, S.; Kim, J.K.; Chung, H.; Lee, H.W.; Chung, H.-Y.; Park, S.D.; Seong, R.H. Notch1 confers a resistance to glucocorticoid-induced apoptosis on developing thymocytes by down-regulating SRG3 expression. Proc. Natl. Acad. Sci. USA 2001, 98, 10267-10272. [CrossRef] [PubMed]

15. Mungamuri, S.; Yang, X.; Thor, A.; Somasundaram, K. Survival signaling by Notch1: Mammalian target of rapamycin (mTOR)-dependent inhibition of p53. Cancer Res. 2006, 66, 4715-4724. [CrossRef] [PubMed]

16. Hollenstein, K.; Frei, D.C.; Locher, K.P. Structure of an ABC transporter in complex with its binding protein. Nature 2007, 446, 213-216. [CrossRef] [PubMed] 
17. Dean, M.; Annilo, T. Evolution of the ATP-binding cassette (ABC) transporter superfamily in vertebrates. Annu. Rev. Genom. Hum. Genet. 2005, 6, 123-142. [CrossRef] [PubMed]

18. Sturm, A.; Cunningham, P.; Dean, M. The ABC transporter gene family of Daphnia pulex. BMC Genom. 2009, 10. [CrossRef] [PubMed]

19. Gottesman, M.M.; Fojo, T.; Bates, S.E. Multidrug resistance in cancer: Role of ATP-dependent transporters. Nat. Rev. Cancer 2002, 2, 48-58. [CrossRef] [PubMed]

20. Haimeur, A.; Conseil, G.; Deeley, R.G.; Cole, S.P.C. The MRP-related and BCRP/ABCG2 multidrug resistance proteins: Biology, substrate specificity and regulation. Curr. Drug Metab. 2004, 5, 21-53. [CrossRef] [PubMed]

21. Igboeli, O.O.; Fast, M.D.; Heumann, J.; Burka, J.F. Role of P-glycoprotein in emamectin benzoate (SLICE®) resistance in sea lice, Lepeophtheirus salmonis. Aquaculture 2012, 344, 40-47. [CrossRef]

22. Scotto, K.W. Transcriptional regulation of ABC drug transporters. Oncogene 2003, 22, 7496-7511. [CrossRef] [PubMed]

23. Cho, S.; Lu, M.; He, X.; Ee, P.-L.R.; Bhat, U.; Schneider, E.; Miele, L.; Beck, W.T. Notch1 regulates the expression of the multidrug resistance gene ABCC1/MRP1 in cultured cancer cells. Proc. Natl. Acad. Sci. USA 2011, 108, 20778-20783. [CrossRef] [PubMed]

24. Morozova, O.; Hirst, M.; Marra, M. Applications of new sequencing technologies for transcriptome analysis. Annu. Rev. Genom. Hum. Genet. 2009, 10, 135-151. [CrossRef] [PubMed]

25. Valenzuela-Munoz, V.; Chavez-Mardones, J.; Gallardo-Escárate, C. RNA-seq analysis evidences multiple gene responses in Caligus rogercresseyi exposed to the anti-salmon lice drug azamethiphos. Aquaculture 2015, 446, 156-166. [CrossRef]

26. SEARCH Consortium. Sea Lice Resistance to Chemotherapeutants: A Handbook in Resistance Management, 2nd ed.; SEARCH: Sacramento, CA, USA, 2006; p. 52.

27. Chavez-Mardones, J.; Gallardo-Escarate, C. Deltamethrin (AlphaMax (TM)) reveals modulation of genes related to oxidative stress in the ectoparasite Caligus rogercresseyi: Implications on delousing drug effectiveness. Aquaculture 2014, 433, 421-429. [CrossRef]

28. Bravo, S.; Sepulveda, M.; Silva, M.; Costello, M. Efficacy of deltamthrin in the control of Caligus rogercresseyi (Boxshall and Bravo) using bath treatment. Aquaculture 2014, 432, 175-180. [CrossRef]

29. Nuñes-Acuña, G.; Gallardo-Escárate, C. Two novel male-associated peroxinectin genes are downregulated by exposure to delousing drugs in Caligus rogercresseyi. Gene 2015, 557, 98-102. [CrossRef] [PubMed]

30. Horsberg, T.E. Avermectin use in aquaculture. Curr. Pharm. Biotechnol. 2012, 13, 1095-1102. [CrossRef] [PubMed]

31. Cline, M.; Smoot, M.; Cerami, E.; Kuchinsky, A.; Landys, N.; Workman, C.; Christmas, R.; Avila-Campilo, I.; Creech, M.; Gross, B.; et al. Integration of biological networks and gene expression data using Cytoscape. Nat. Protoc. 2007, 2, 2366-2382. [CrossRef] [PubMed]

32. Newman, M.; Wilson, L.; Verdile, G.; Lim, A.; Khan, I. Differential, dominant activation and inhibition of Notch signalling and APP cleavage by truncations of PSEN1 in human disease. Hum. Mol. Genet. 2014, 23, 602-617. [CrossRef] [PubMed]

33. Gulino, A.; di Marcotullio, L.; Screpanti, I. The multiple functions of Numb. Exp. Cell Res. 2010, 316, 900-906. [CrossRef] [PubMed]

34. Buscarlet, M.; Stifani, S. The "Marx" of Groucho on development and disease. Trends Cell Biol. 2007, 17, 353-361. [CrossRef] [PubMed]

35. Fisher, A.L.; Caudy, M. Groucho proteins: Transcriptional corepressors for specific subsets of DNA-binding transcription factors in vertebrates and invertebrates. Gene Dev. 1998, 12, 1931-1940. [CrossRef] [PubMed]

36. Zhang, D.C.; Jiang, S.G.; Hu, Y.T.; Cui, S.G.; Guo, H.Y.; Wu, K.C.; Li, Y.N.; Su, T.F. A multidomain galectin involved in innate immune response of pearl oyster Pinctada fucata. Dev. Comp. Immunol. 2011, 35, 1-6. [CrossRef] [PubMed]

37. Pohl, P.; Klafke, G.; Júnior, J.R.; Martins, J.R.; Silva Vaz, I., Jr.; Masuda, A. ABC transporters as a multidrug detoxification mechanism in Rhipicephalus (Boophilus) microplus. Parasitol. Res. 2012, 111, 2345-2351. [CrossRef] [PubMed]

38. Carcamo, J.G.; Aguilar, M.N.; Barrientos, C.A.; Carreno, C.F.; Quezada, C.A.; Bustos, C.; Manriquez, R.A.; Avendano-Herrera, R.; Yanez, A.J. Effect of emamectin benzoate on transcriptional expression of cytochromes P450 and the multidrug transporters (Pgp and MRP1) in rainbow trout (Oncorhynchus mykiss) and the sea lice Caligus rogercresseyi. Aquaculture 2011, 321, 207-215. [CrossRef] 
39. Mamidala, P.; Wijeratne, A.; Wijeratne, S.; Kornacker, K.; Sudhamalla, B.; Rivera-Vega, L.; Hoelmer, A.; Meulia, T.; Jones, S.; Mittapalli, O. RNA-Seq and molecular docking reveal multi-level pesticide resistance in the bed bug. BMC Genom. 2012, 13. [CrossRef] [PubMed]

40. Geneious. Available online: http://www.geneious.com (accessed on 25 February 2016).

41. Morris, J.H.; Apeltsin, L.; Newman, A.M.; Baumbach, J.; Wittkop, T.; Su, G. Clustermaker: A multi-algorithm clustering plugin for Cytoscape. BMC Bioinform. 2011, 12. [CrossRef] [PubMed]

42. Czerwinska, U.; Calzone, L.; Barillot, E.; Zinovyev, A. DeDaL: Cytoscape 3.0 app for producing and morphing data-driven and structure-driven network layouts. BMC Syst. Biol. 2015, 9. [CrossRef] [PubMed]

43. Benjamini, Y.; Hochberg, Y. Controlling the False Discovery Rate: A Practical and Powerful Approach to Multiple Testing. J. R. Stat. Soc. Ser. B 1995, 57, 289-300.

44. Gorban, A.N.; Zinovyev, A. Principal graphs and manifolds. In Handbook of Research on Machine Learning Applications and Trends: Algorithms, Methods and Techniques; Olivas, E., Guererro, J., Sober, M., Benedito, J., Lopes, A., Eds.; IGI Global: Hershey, PA, USA, 2009.

(C) 2016 by the authors; licensee MDPI, Basel, Switzerland. This article is an open access article distributed under the terms and conditions of the Creative Commons Attribution (CC-BY) license (http://creativecommons.org/licenses/by/4.0/). 